\title{
American Board of Family Medicine and Maintenance of Certification for Family Physicians: Second Cohort on Path to 3-Year Extension
}

The American Board of Family Medicine (ABFM) is pleased to announce that more than 9000 of the Diplomates who certified or recertified in 2004 successfully met the deadline to complete their Stage One requirements for Maintenance of Certification for Family Physicians (MC-FP). By completing these requirements, these Diplomates are eligible to remain on track for the 3-year extension of their current certificate, creating a 10 -year certificate. The 2004 Diplomates are the second group to complete Stage One, almost matching the number of 2003 Diplomates who successfully completed Stage One the previous year. Of the 2004 Diplomates, $80 \%$ have successfully completed Stage One requirements, compared with $81 \%$ of 2003 Diplomates who successfully completed Stage One requirements.

The first 3-year stage of the MC-FP process requires completing either 3 Part II Modules (SelfAssessment Modules [SAMs]), or 2 Part II Modules and 1 Part IV Module (Performance in Practice Module [PPM] or approved alternate). The ABFM recently announced that all participants who begin MC-FP during 2004 to 2010 will have the choice of completing 2 Part II modules and 1 Part IV module or 3 Part II modules to fulfill Stage One requirements.

Stage Two and Stage Three both require the completion of 2 Part II Modules (SAMs) and 1 Part IV Module (PPM or approved alternate). The 2004 group must successfully complete Stage Two requirements by December 31, 2010, after which
Diplomates will earn the 3-year extension to their 7-year certificate. These requirements may be completed any time before the deadline, and the ABFM website will immediately indicate the 3 -year extension; however, the 10-year certificate will not be mailed to the Diplomates until the end of Stage Two (December 31, 2010).

MC-FP consists of 4 elements, each designed to assess 4 important physician characteristics: professionalism (Part I), self-assessment and lifelong learning (Part II), cognitive expertise (Part III), and performance in practice (Part IV). The requirements for each of the 3 3-year Stages, as explained above, fulfill Part II and Part IV of MC-FP. Professionalism (Part I) requires a currently valid, full, and unrestricted license to practice medicine in the United States or Canada. Cognitive Expertise (Part III) involves the successful completion of a cognitive examination.

After a Diplomate has entered MC-FP, all components must be completed to be eligible to sit for the examination. Failure to pass the cognitive examination by the end of the MC-FP cycle results in the loss of certification. To begin MC-FP or to keep track of MC-FP progress, Diplomates may visit the ABFM website at www.theabfm.org and $\log$ on to the physician's portfolio section. The ABFM has updated its website to reflect the 7-year or 10 -year track chosen by the Diplomate.

Jane Ireland American Board of Family Medicine Communications 